If these rules are followed, the damage associated with poisoning with ChE-I most likely will remain limited. Key Words: carbamates; organophosphates; poisoning

\section{Telecommunication in an Earthquake Disaster} Shuuichi Okumura, $M D$; ${ }^{*}$ Yoshio Murayama, $M D$

*Vice Director of Hospital, Kobe National Hospital, Kobe, Japan

Telephone communication is one of the most popular ways for people to communicate with each other. In the earthquake disaster, the telephone still is very useful. However, in Japan, the telephone companies automatically restrict $95 \%$ of the public telephone lines in order to maintain the emergency lines in the area stricken by the quake. Approximately $30-40 \%$ of the telephone lines of hospitals are secured as the emergency lines. Just after an earthquake like the Hanshin-Awaji Great Earthquake Disaster, numerous calls attempted to gain access to the limited number of emergency lines. Consequently, the important lines became busy. On the other hand, the fax numbers are not well-known. It is comparatively easy to communicate with other facilities or hospitals by fax.

The Internet is a durable communicating network system against the disaster and is a useful global tool. And yet, it is too busy for the people living in the hard stricken area to use, especially to build up a home-page to let the people in other areas know the necessary information including the damages. This presentation will detail the problems of the telephone communication and the Internet.

Key Words: earthquake; Internet; telephone

\section{Session 2: Miscellaneous \\ Chairpersons: Ch. Lexow (Norway) A. Barelli (Italy)}

\section{Application of Plasmapheresis in Emergency Treatment of Opiate Withdrawal Syndrome Dr. Vitaly Pishel}

Ukrainian Research Institute of Social and Forensic Psychiatry, Kyiv, Ukraine

The application of plasmapheresis is reported as a powerful method of extracorporeal detoxicification in the emergency treatment of the opiate withdrawal syndrome, a life-threatening condition. We studied this group of patients, aged from 18 to 32 years with average duration of disease $4.9 \pm 1.7$ years. When narcotics were withdrawn, all of the patients exhibited a pronounced physical dependence withdrawal syndrome manifested by a progression of severe somatic-vegetative, algetic, and psycho-pathologic disturbances. Individual doses of narcotics ranged from 6.0 to $15.0 \mathrm{ml}$ per day of a hand-made solution of papaverous straw distributed over 2-3 doses.

As a rule, the procedure of plasmapheresis was performed daily for 3 days. In a single session, $600-800 \mathrm{ml}$ of plasma was extracted, followed by its substitution with a colloidal or crystalloid solution. The major somatic-vegetative and algetic manifestations of withdrawal syndrome stopped on the third or fourth day after admission to the hospital.

It is vital to note the observed decrease in pharmacological resistance to psychotropic drugs and analgesics made possible by the plasmapheresis. The procedure corrected the main biochemical indices and reduced endogenous intoxication. The findings indicate that plasmapheresis is a powerful, pathogenically-substantiated and economically-beneficial method of emergency treatment to opiate addicts.

Key Words: addiction; aid plasmapheresis; emergency; opiate withdrawal syndrome

\section{Outbreak of Salmonellosis at a School \\ V.P. Popov; O.V. Kolasnikov \\ Center of Disaster Medicine, Ekaterinburg, Russia}

An incident of food toxico-infection among the children of Krasnoufimsk school was reported to the controller's office of the Center of Disaster Medicine on 24 November 1994 at 10:25 hours. More than 100 people with the symptoms of this disease of different levels of severity were admitted to the local hospital.

A decision was made to send a group of specialists and drugs to the hospital to help in treating the affected patients. This group consisted of three anaesthesiologist-reanimatologists, an infection control specialist, and three nurses. A complex of medicines and medical technologies was prepared. They included: solutions for infusion, antibiotics, steroids, systems for infusion, machines for artificial lung ventilation, and disinfectants. At 14:25 hours, the specialist went by a helicopter "MI-8" to Krasnoufimsk. There, they determined the outbreak was a toxic infection caused by Salmonella due to a breach of cooking practices. There were 940 pupils at the school, about 40 teachers, and 60 members of personnel. There were 105 children, aged 7-15 years and five adults who were hospitalized and approximately 130 children were treated at home due to the infection.

A specialist from the Center categorized the sick people and identified 55 who required intravenous infusion of fluids. Intensive care rooms were organized for them. The Center specialists admitted 43 patients, 33 children, and 10 adults to the hospital. The most severely ill patients received intravenous infusion and medical therapy. They were kept under observation. Scientists of Ekaterinburg Medical Academy participated in the treatment of the most severely ill patients.

On 28 November 1994, due to the stabilization of the medical situation and absence of new cases of infection, the specialists returned to Ekaterinburg. Later, under the Center's control, all the patients recovered from Salmonellosis.

Key Words: contaminated food; infection; salmonellosis 